\title{
Occurrence and human exposure of parabens and their chlorinated derivatives in swimming pools
}

\author{
Wenhui $\mathrm{Li}^{1} \cdot$ Yali Shi $^{2} \cdot \operatorname{Lihong~Gao}{ }^{1} \cdot \mathrm{Jiemin} \mathrm{Liu}^{1} \cdot$ Yaqi Cai $^{2}$
}

Received: 26 April 2015 / Accepted: 7 July 2015 /Published online: 15 July 2015

(C) Springer-Verlag Berlin Heidelberg 2015

\begin{abstract}
As an emerging group of endocrine-disrupting chemicals, parabens have attracted growing attention due to their potential effects on human health. In the present study, the occurrence and distribution of eight parabens, four chlorinated parabens, and their common hydrolysis product, $p$ hydroxybenzoic acid (PHBA), were investigated in 39 swimming pools in Beijing, China. Methyl paraben and propyl paraben were the predominant compounds in swimming pools, accounting for $91.2 \%$ of the total parabens. It is noteworthy that octyl paraben, a paraben with longer chain, was firstly detected in this study. There were several factors affecting the levels of parabens among the 39 swimming pools. The concentrations of parabens and chlorinated derivatives detected in indoor pools ( $144 \mathrm{ng} \mathrm{L}^{-1}$ ) were roughly 20 -fold higher than those in outdoor pools $\left(6.78 \mathrm{ng} \mathrm{L}^{-1}\right)$. Hotel pools appear to present higher level of target compounds $\left(361 \mathrm{ng} \mathrm{L}^{-1}\right)$ than that in health club $\left(228 \mathrm{ng} \mathrm{L}^{-1}\right)$, municipal $\left(130 \mathrm{ng} \mathrm{L}^{-1}\right)$, school (75.6 $\left.\mathrm{ng} \mathrm{L}^{-1}\right)$, and community pools $\left(63.0 \mathrm{ng} \mathrm{L}^{-1}\right)$. Moreover, the level of these compounds in pools during
\end{abstract}

Responsible editor: Hongwen Sun

Electronic supplementary material The online version of this article (doi:10.1007/s11356-015-5050-1) contains supplementary material, which is available to authorized users.

Jiemin Liu

liujm@ustb.edu.cn

Yaqi Cai

caiyaqi@rcees.ac.cn

1 School of Chemistry and Biological Engineering, University of Science and Technology Beijing, Beijing 100083, China

2 State Key Laboratory of Environmental Chemistry and Ecotoxicology, Research Center for Eco-Environmental Science, Chinese Academy of Sciences, Beijing 100085, China weekends (174 $\left.\mathrm{ng} \mathrm{L}^{-1}\right)$ was much higher than that during weekdays $\left(52.3 \mathrm{ng} \mathrm{L}^{-1}\right)$. The dynamics of target compounds were also investigated to provide a general trend of the level of parabens in a school indoor swimming pool during a 14-week period. Human exposure assessment was conducted to estimate the potential risk of exposure to parabens and their chlorinated derivatives in swimming pools. Considering the total exposure dose of multiple parabens, human exposure to parabens from the water of swimming pools is negligible. However, the threat of these parabens to children in swimming pool should be concerned.

Keywords Parabens $\cdot$ Chlorinated parabens $\cdot$ PHBA . Swimming pool $\cdot$ Human exposure assessment

\section{Introduction}

Swimming is a popular leisure activity, which can provide health benefits for the public. However, growing studies suggest that exposure to the water in swimming pools may result in a variety of health risks, such as increased asthma and allergy, which are associated with microbial and chemical hazards (Bernard et al. 2006; Pasquarella et al. 2013, 2014). Recent studies have raised concerns on adverse health impacts associated with application of personal care products and disinfection by-products (DBPs) formed in swimming pools (Chowdhury et al. 2014; Kim et al. 2002; Xiao et al. 2012). The presence of pollutants originating from the application of preservatives has been reported in swimming pools (Teo et al. 2015; Terasaki and Makino 2008).

Parabens, a group of alkyl esters of $p$-hydroxybenzoic acid (PHBA), are widely applied as antimicrobial preservatives in foods, cosmetics, and pharmaceuticals (Guo et al. 2014; Yamamoto et al. 2011). In general, parabens are moderately 
soluble in water, and the increased length of the alkyl chain can result in decreased solubility. Instead, the values of octanol-water partition coefficients reveal an increase as the extension of chain length (from 1.66 to 4.88 ). These compounds are not volatile because of their low Henry's law constants (from $2.92 \times 10^{-10}$ to $1.98 \times 10^{-8} \mathrm{~atm} \mathrm{~m}^{3} \mathrm{~mol}^{-1}$ ) (Bledzka et al. 2014; Haman et al. 2015; Wang et al. 2012). As the routine preservatives in various cosmetics and sun care products, parabens may be introduced by a large number of swimmers into the water of swimming pools. In addition, due to the active phenolic hydroxyl groups, parabens can be easily transformed to mono- and di-chlorinated derivatives in chlorinated water (Terasaki et al. 2012; Westerhoff et al. 2005). Therefore, parabens may react with free chlorine to form chlorinated parabens during disinfection of swimming pool water, which are more stable in environment and more toxic than the corresponding parent parabens (Bledzka et al. 2014; Terasaki et al. 2009). These compounds may continuously accumulate and increase in swimming pools (Zwiener et al. 2007). Thus, humans may be exposed to parabens and their chlorinated derivatives via different pathways in swimming pools (i.e., inhalation, ingestion, and dermal absorption) (Bedoux et al. 2012; Karpuzoglu et al. 2013).

Several studies have demonstrated that parabens and chlorinated derivatives exhibit endocrine-disrupting properties, which may modulate or disrupt the endocrine system and have harmful effects on animal and human health (Piao et al. 2014; Tavares et al. 2009). Epidemiological studies have shown an association between human exposure to parabens and adverse health outcomes (Meeker et al. 2011; Savage et al. 2012). In March 2011, Denmark has banned the application of propyl paraben, butyl paraben, and their salts in cosmetic products for children under 3 years old (Asimakopoulos et al. 2014). Therefore, more attention should be paid to the potential risks of exposure to these compounds, especially for the children, who are more likely to be adversely affected by environmental contaminants than adults due to their lower body weights, rapidly undergoing behavioral and physical development (Harvey and Everett 2006; Ngo and Maibach 2010).

So far, there is very scarce data available on the presence of parabens and their chlorinated derivatives in pool water samples (Haman et al. 2015). Parabens are only analyzed in limited swimming pool water samples by gas chromatography with flame-ionization detection (GC-FID) (Lopez-Darias et al. 2010), gas chromatography-mass spectrometry (GCMS) (Terasaki and Makino 2008) and gas chromatographytandem mass spectrometry (GC-MS/MS) (Regueiro et al. 2009a, b). Although parabens are widely applied in personal care products, with the exception of butyl paraben, benzyl paraben, and di-chlorinated propyl paraben, most parabens and their chlorinated derivatives are not found in the water samples. Surprisingly, methyl paraben, one of the most commonly used parabens, is also free of swimming pool water samples. Therefore, it is required to further investigate the pollution level of parabens in more swimming pools.

In the present study, the occurrence and distribution of 13 target compounds, including eight parabens, PHBA, and four chlorinated derivatives, were simultaneously determined in water samples collected from 39 swimming pools in Beijing. The objectives of this study were to examine the levels of target compounds in swimming pools and estimate potential risks resulting from the exposure to these compounds in swimming pools. The results obtained in this study will be important for the assessment of human exposure in swimming pools.

\section{Materials and methods}

\section{Standards and reagents}

HPLC-grade methanol and acetonitrile were purchased from Fisher Scientific (Pittsburgh, PA, USA); ammonium acetate (99 \%) was purchased from Alfa Aesar (USA). All purity water $\left(>18.2 \mathrm{M} \Omega \mathrm{cm}^{-1}\right)$ was prepared with Milli-Q Advantage A10 system (Millipore, USA).

Analytical standards of $p$-hydroxybenzoic acid (PHBA, $100 \%$ ), methyl paraben (MeP, $97.5 \%$ ), ethyl paraben (EtP, $99.0 \%$ ), propyl paraben (PrP, $99.3 \%$ ), butyl paraben (Bup, $100 \%$ ), pentyl paraben (PeP, $98.0 \%$ ), heptyl paraben (HeP, $99.0 \%$ ), benzyl paraben (BzP, $100 \%$ ), octyl paraben (OcP, $98.0 \%$ ), methyl 3-chloro-4-hydroxybenzoate (3-Cl-MeP, 98.0\%), methyl 3,5-dichloro-4-hydroxybenzoate (3,5-2ClMeP, $98.0 \%$ ), ethyl 3-chloro-4-hydroxybenzoate (3-Cl-EtP, $97.0 \%$ ), and ethyl 3,5-dichloro-4-hydroxybenzoate (3,52Cl-EtP, $98.0 \%$ ) were purchased from AccuStandard Inc (New Haven, CT, USA).

The following isotopically labeled compounds were used as surrogate standards (500.0 $\mu \mathrm{g} \mathrm{L}^{-1}$ in methanol): $p$-hydroxybenzoic acid- $\mathrm{d}_{4}\left(\right.$ PHBA- $\left.\mathrm{d}_{4}\right)$, methyl paraben$\mathrm{d}_{4}\left(\right.$ MeP- $\left.\mathrm{d}_{4}\right)$, ethyl paraben- $\mathrm{d}_{5}\left(\right.$ EtP- $\left.\mathrm{d}_{5}\right)$, propyl paraben$\mathrm{d}_{7}\left(\mathrm{PrP}-\mathrm{d}_{7}\right)$, paraben- $\mathrm{d}_{9}\left(\right.$ BuP- $\left.\mathrm{d}_{9}\right)$, and benzyl paraben- $\mathrm{d}_{9}$ $\left(B z P-d_{7}\right)$ were purchased from Toronto Research Chemicals (Oakville, ON, Canada). The physicochemical characteristics of the test parabens are listed in Table S1 in the supplementary materials.

\section{Sample collection}

In the present study, a total of 39 different swimming pools located in Beijing were investigated during the period of August 2013 to June 2014. Swimming pools were chosen in various functional areas and public areas (municipal), hotels, health clubs, schools, and communities. All swimming pools were disinfected by treatment with chlorine or a combination 
of ozone and free chlorine. Detailed information of each swimming pool is listed in Table S2.

To investigate the temporal variation of parabens and their chlorinated derivatives, one indoor school pool was sampled weekly (14 times) from March to June 2014. In order to reduce the influence by the water renewal, only the pool water samples spaced above 15 days from the last renewal were collected in this study. All pool water samples were collected in 1-L amber glass bottles, which were washed with methanol and DI water before use. Two water samples from each pool were collected from approximately $30 \mathrm{~cm}$ below the water surface, and the excessive free chlorine present in water samples was removed by adding ascorbic acid to avoid further reacting with parabens. All water samples were kept in a portable fridge and transported to the laboratory as soon as possible and then kept at $4{ }^{\circ} \mathrm{C}$ and analyzed within $48 \mathrm{~h}$ to avoid storage loss.

\section{Sample preparation and analysis}

Target compounds were extracted from water samples using AutoTrace SPE 280 (Dionex, USA) with an Oasis HLB cartridge (6 mL, $200 \mathrm{mg}$; Waters, USA), as described in a previous study with some modifications (Gonzalez-Marino et al. 2009). The water samples were adjusted to $\mathrm{pH} 2$ with $1.0 \mathrm{M}$ $\mathrm{H}_{2} \mathrm{SO}_{4}$ and $\mathrm{NaOH}$. A total of $20 \mathrm{ng}$ surrogate standards

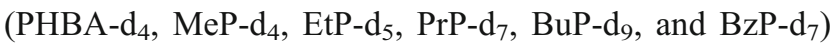
were added to $500 \mathrm{~mL}$ water sample before the mixture were extracted with the Oasis HLB cartridge. The HLB cartridges were conditioned with $5 \mathrm{~mL}$ methanol and $5 \mathrm{~mL}$ DI water. After loaded with samples, cartridges were washed with $6 \mathrm{~mL}$ DI water and then dried under a nitrogen stream for $30 \mathrm{~min}$. The target analytes were eluted with $6 \mathrm{~mL}$ of methanol, and the eluate was concentrated to $1 \mathrm{~mL}$ with a stream of nitrogen at $35^{\circ} \mathrm{C}$. Finally, the concentrate was filtered through a $0.45-\mu \mathrm{m}$ nylon membrane (Whatman, Maidstone, UK), and an aliquot $(15 \mu \mathrm{L})$ of this solution was injected into the high-performance liquid chromatography-electrospray ionization tandem mass spectrometry (HPLC-ESI MS/MS) system for analysis.

\section{Liquid chromatography/tandem mass spectrometry}

Chemical analysis was performed with a Dionex (Sunnyvale, CA, USA) Ultimate 3000 HPLC system coupled with an Applied Biosystems API 3200 triple quadrupole mass spectrometer (Foster City, CA, USA) equipped with an electrospray ionization source. An Acclaim Mixed-Mode HILIC-1 column ( $3 \mu \mathrm{m}, 2 \mathrm{~mm} \times 150 \mathrm{~mm}$; Thermo, USA) was used as the analytical column at a flow rate of $0.20 \mathrm{~mL} \mathrm{~min}^{-1}$. Acetonitrile was used as mobile phase $\mathrm{A}$, and $0.1 \%$ ammonium formate in water was used as mobile phase B. The gradient program was as follows: The mobile phase starting conditions were $40 \%$ of A for $2.0 \mathrm{~min}$, and A was increased to $55 \%$ in $3.0 \mathrm{~min}$ before being increased to $100 \%$ in $6.0 \mathrm{~min} ; 100 \%$ of A for $4.0 \mathrm{~min}$, followed by returning to the initial composition in $1 \mathrm{~min}$, which was maintained for $9.0 \mathrm{~min}$. The total run time was $25.0 \mathrm{~min}$.

The MS system was operated in the negative electrospray ionization and multiple reactions monitoring (MRM) mode. The MS/MS parameters were optimized as follows: curtain gas pressure, 0.07 $\mathrm{MPa}$; collision gas pressure, $0.02 \mathrm{MPa}$; ion spray voltage, $-4500 \mathrm{~V}$; temperature, $450{ }^{\circ} \mathrm{C}$; gas 1 , $0.31 \mathrm{MPa}$; and gas 2, $0.31 \mathrm{MPa}$. Other parameters of MS/ MS and ion pair are listed in Table S3.

\section{Quantification and quality control}

All containers were rinsed with methanol and water before use to avoid analytical interference and/or cross-contamination. Quantification of the analytes was based on an internal standard method, and the concentrations were corrected for the recoveries of the internal standards. The calibration curve was prepared within a wide range of concentrations $(0.01-$ $\left.500 \mu \mathrm{g} \mathrm{L}^{-1}\right)$ to reveal strong linearity $\left(r^{2}>0.99\right)$. The instrumental detection limit was determined as the minimum detectable concentration of an analyte with a signal-to-noise ratio of 3. With every 10 samples, a procedural blank and a field blank were analyzed to control travel contamination and laboratory contamination. A $10 \mu \mathrm{g} \mathrm{L}^{-1}$ standard was set as the quality control concentration to ensure analytical stability and to verify calibration. Detailed information on the recovery rates (\%) and method detection limits (MDLs) was listed in Table S4 in the supplementary materials.

\section{Statistical analysis}

All statistical analyses were performed with IBM SPSS Statistics 20.0 (SPSS Inc., Chicago, USA). The total concentration of parabens $\left(\sum \mathrm{PBs}\right)$ was the sum concentration of eight individual parabens, and $\sum$ Cl-PBs was the sum concentration of four individual chlorinated parabens analyzed in this study. A nonparametric Spearman correlation was performed to assess correlations among the concentrations of several parabens in the swimming pool water. The normality test of the data was analyzed using a Kolmogorov-Smirnov test. The comparison of concentrations was performed using the nonparametric Kruskal-Wallis test. The significant difference was considered at $p<0.05$.

\section{Results and discussion}

\section{Concentrations of parabens, chlorinated parabens, and PHBA}

The concentrations of 13 target compounds present in swimming pool water samples were summarized in Table 1. As can be seen, PHBA, seven parabens (MeP, EtP, PrP, BuP, HeP, $\mathrm{BzP}$, and $\mathrm{OcP}$ ), and four chlorinated parabens (3-Cl-Mep, 3- 
Table 1 Concentrations of target compounds in water from 39 swimming pools (ng L ${ }^{-1}$ )

\begin{tabular}{llllll}
\hline Analytes & Maximum & Minimum & Median & Mean & $\begin{array}{l}\text { Detection rate } \\
(\%)\end{array}$ \\
\hline MeP & 872 & 0.16 & 5.32 & 85.7 & 100 \\
EtP & 110 & nd & 0.56 & 6.59 & 56 \\
PrP & 266 & nd & 0.13 & 18.4 & 62 \\
BuP & 49.2 & nd & nd & 2.02 & 46 \\
PeP & nd & nd & nd & nd & 0 \\
HeP & 0.06 & nd & nd & nd & 8 \\
BzP & 6.52 & nd & 0.54 & 1.16 & 72 \\
OcP & 0.69 & nd & 0.13 & 0.18 & 64 \\
3-Cl-MeP & 7.49 & nd & 0.47 & 1.49 & 82 \\
3,5-2Cl-MeP & 36.2 & 0.22 & 2.86 & 4.87 & 100 \\
3-Cl-EtP & 0.64 & nd & nd & 0.02 & 5 \\
3,5-2Cl-EtP & 24.2 & 0.40 & 11.3 & 11.1 & 100 \\
PHBA & 1122 & nd & 181 & 261 & 95 \\
\hline
\end{tabular}

$n d$ not detected

Cl-Etp, 3,5-2Cl-MeP, and 3,5-2Cl-EtP) were detected in swimming pool water samples.

Among all parabens, MeP was the most abundant compound with the highest mean concentration of $85.7 \mathrm{ng} \mathrm{L}^{-1}$, followed by PrP with a mean concentration of $18.4 \mathrm{ng} \mathrm{L}^{-1}$. $\mathrm{MeP}$ and $\mathrm{PrP}$ were the most frequently detected parabens $(100 \%)$ in swimming pool water samples, which may be attributed to their high solubility in water and common application in most cosmetic formulations. The mean concentrations of EtP, BuP, BzP, and OcP were only 6.59, 2.02, 1.16, and $0.18 \mathrm{ng} \mathrm{L}^{-1}$, respectively, although they were frequently found in these water samples (46-72\%). It should be noted that OcP, which had not been reported in previous studies before, was also detected in the swimming pool samples in the present study. Owing to the greatest antimicrobial effect, OcP was frequently used as a preservative in high-quality cosmetics. Various published studies have reported that parabens with longer linear chains are generally more potent than those with shorter chains, and their persistence seems to increase with the length of the alkyl chain (Andersen 2008; Brausch and Rand 2011; Nunez et al. 2008). Considering the structures of target parabens, OcP, a paraben with a longer chain, shows the strongest estrogenic activity and persistence and may be potential threat to swimmers' health (Golden et al. 2005). HeP was only detected in three samples at relatively low level $\left(0.02 \mathrm{ng} \mathrm{L}^{-1}\right)$, while the concentration of PeP was below its MDL in all samples. The absence of $\mathrm{HeP}$ and $\mathrm{PeP}$ in most samples may be well explained by the fact that both kinds of parabens are rarely used as antimicrobial agents in cosmetics, which will be excluded from the following discussion. In general, the relative concentrations of measured parabens reflect their consumption patterns in this area.
As the main metabolite or degradation product of parabens, PHBA was frequently found in pool water samples, with a mean concentration of $264 \mathrm{ng} \mathrm{L}^{-1}$. It is reported that PHBA can also cause physiological estrogenic responses (Boberg et al. 2010; Dobbins et al. 2009; Gonzalez-Doncel et al. 2014). Although it is less toxic than parabens (Ishiwatari et al. 2007), the relative high level of PHBA in swimming pools cannot be neglected.

Chlorinated parabens were frequently found in swimming pool water samples, because parabens are widely used in personal care products and highly reactive with chlorine in swimming pool water. It should be noted that chlorinated parabens, such as 3,5-2Cl-EtP, were detected at higher levels than the corresponding parent compounds (Table 1). In addition, we also found that the levels of di-chlorinated parabens, 3,5-2Cl$\mathrm{MeP}\left(4.87 \mathrm{ng} \mathrm{L}^{-1}\right)$ and 3,5-2Cl-EtP $\left(11.1 \mathrm{ng} \mathrm{L}^{-1}\right)$, were much higher than those of mono-chlorinated parabens, 3-Cl-Mep (1.49 $\left.\mathrm{ng} \mathrm{L}^{-1}\right)$ and 3-Cl-Etp $\left(0.02 \mathrm{ng} \mathrm{L}^{-1}\right)$, in pool water samples in this study. This may be due to the fact that the dichlorinated parabens are more stable than mono-chlorinated ones in the aquatic environment. Moreover, the di-chlorinated parabens are highly resistant to undergo further chlorine substitution reactions (Canosa et al. 2006).

To date, only four studies have reported the occurrence and behavior of parabens and their chlorinated derivatives in limited swimming pool water samples in Japan (Terasaki and Makino 2008) and Spain (Lopez-Darias et al. 2010; Regueiro et al. 2009a, b). However, with the exception of PrP (32 $\left.\mathrm{ng} \mathrm{L}^{-1}\right)$, BuP (13 ng L $\left.{ }^{-1}\right)$, BzP $\left(28 \mathrm{ng} \mathrm{L}^{-1}\right)$, and dichlorinated $\operatorname{PrP}\left(25 \mathrm{ng} \mathrm{L}^{-1}\right)$ in sporadic samples, all the parabens and chlorine derivatives were virtually absent in the water samples. It is surprising that MeP, one of the most commonly used parabens, which was frequently found at high level in our study, was also free of swimming pool water samples collected from Japan and Spain. The possible reasons for this result can be summarized as follows: Firstly, the consumption pattern of parabens in Beijing was significantly different from that in Japan and Spain, and the high concentrations of parabens actually reflect the pollution levels of in this area. Secondly, compared to previous reports with GC-MS, the LC-MS/MS method applied in this study was sensitive enough to detect the trace levels of parabens present in water of swimming pools. Finally, if the addition of sodium thiosulfate or ascorbic acid was not enough to remove the excessive of free chlorine present in water samples, parabens may further reacted with the rest of free chlorine, leading to their relatively low levels and detection frequencies in these reports.

Compared with other environmental water samples, the concentrations of parabens and their chlorinated derivatives in swimming pool water samples in the present study were approximately one to two orders of magnitude higher than those found in tap water (Carmona et al. 2014), river water (Terasaki et al. 2012), and marine water (Jonkers et al. 2010), 
even in the same order of magnitude as those in influents of wastewater treatment plants (Jonkers et al. 2009; Lee et al. 2005), indicting that the levels of target compounds in the swimming pool are relatively high. Thus, the potential risks due to long-term exposure to swimming pool water containing parabens and their chlorinated derivatives should be paid more attention.

\section{Comparison of different pools}

As illustrated in Fig. 1, the swimming pool water samples from 39 pools showed very similar composition profiles of parabens, indicating their universal usages. Composition analysis also indicated that $\mathrm{MeP}$ and $\mathrm{PrP}$ were the predominant parabens in swimming pools, which accounted in average for $91.2 \%$ of the total parabens. The concentrations of total parabens and chlorinated derivatives in different pools are summarized in Fig. 2. The highest level of these compounds (1318 $\left.\mathrm{ng} \mathrm{L}^{-1}\right)$ was found in $\mathrm{S} 31$, while the lowest level (1.74 $\left.\mathrm{n} \mathrm{L} \mathrm{L}^{-1}\right)$ was found in S18. In general, significant differences were observed for the total concentrations of target compounds among the 39 pools $(p<0.05)$. In order to assess the potential factors affecting the paraben levels in different pools, related information, such as characteristics of pools and total organic carbon (TOC), operational conditions, and sampling time, was investigated.

The sum concentrations of parabens and chlorinated derivatives in the swimming pool water samples were found in a decreasing order as hotel $\left(361 \mathrm{ng} \mathrm{L}^{-1}\right)>$ health club $\left(228 \mathrm{ng} \mathrm{L}^{-1}\right)>$ municipal $\left(130 \mathrm{ng} \mathrm{L}^{-1}\right)>$ school (75.6 ng L ${ }^{-1}$ ) > community (63.0 ng L ${ }^{-1}$ ) (Fig. 3). Because cosmetics and personal care products are an important source of paraben contamination in swimming pool water, the levels of parabens may be related to higher bather loading to some extent (Wang et al. 2012). The Spearman's coefficients of the concentrations of parabens and ticket prices are present in Table S5. Significant correlation between the total concentration of these compounds and ticket prices was found in these samples $(R=0.326, p<0.05)$, indicating that the concentrations of parabens were correlated with the personal consumption expenditure to some extent. Generally, hotel pools are small in size and high in price, while the per capita consumption of cosmetics and skin care products containing parabens by these consumers were usually higher than those for other pools. Therefore, hotel pools appear to present higher levels of parabens than those in other kinds of pools.

In the present study, a total of 39 public swimming pools, including 35 indoor pools and 4 outdoor pools were investigated. The sum concentration of parabens and chlorinated derivatives varied significantly between indoor and outdoor swimming pools $(R=0.632, p<0.05)$. As illustrated in Fig. S1, the concentrations of these compounds detected in indoor pools (mean $144 \mathrm{ng} \mathrm{L}^{-1}$ ) were roughly 20 -fold higher than those in outdoor pools (mean $6.78 \mathrm{ng} \mathrm{L}^{-1}$ ). This result is consistent with previous reports that concentrations of DBPs in indoor pools were higher than those in outdoor pools (Xiao et al. 2012; Yeh et al. 2014). Compared to the indoor pools, opening times for outdoor pools are usually short. Therefore, outdoor pools may have a relatively low paraben loading. In addition, the outdoor pools are subjected to prolong exposure to sunlight, which could increase the photodegradation rates of parabens. This result indicates a high level of paraben exposure to swimmers in indoor swimming pools.

It is reported that the highest number of bathers is expected to be on the holidays and weekends (Abd El-Salam 2012). Therefore, sampling time may be an important factor affecting the paraben levels in pools. As shown in Table S2, 25 pool water samples were collected on the weekends, while the

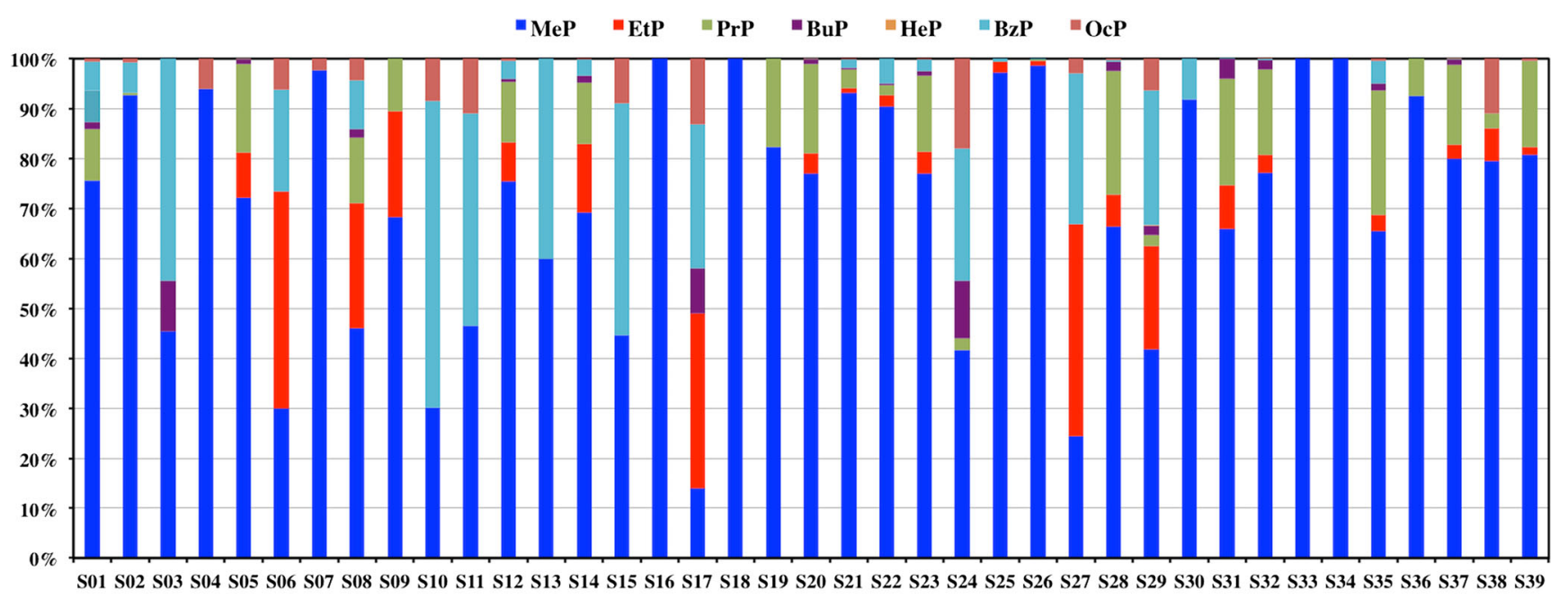

Sampling sites

Fig. 1 Composition profiles of eight parabens in 39 pool water samples 


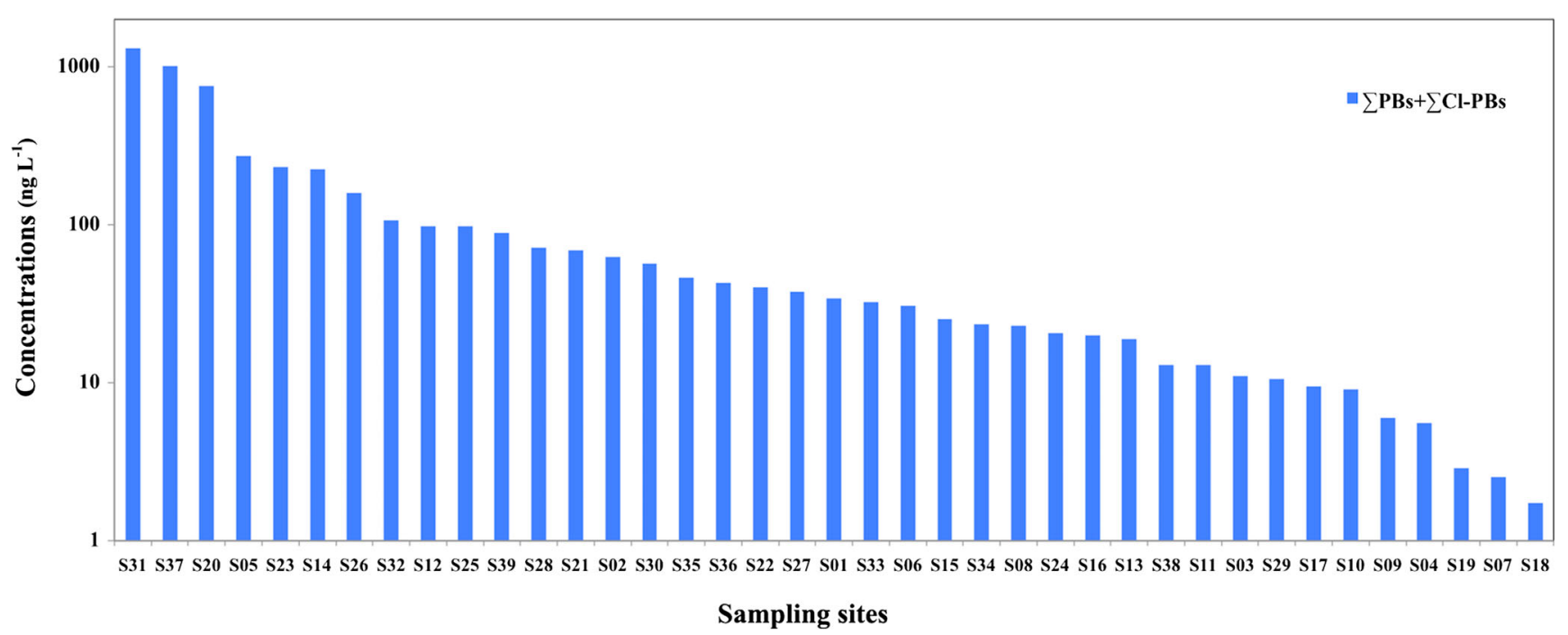

Fig. 2 The total concentrations of parabens and chlorinated parabens in 39 swimming pools

other 14 samples were collected on the weekdays. The concentrations of parabens and chlorinated derivatives from different sampling time are illustrated in Fig. S2. It was obvious that the levels of these compounds in pools during weekends (mean $174 \mathrm{ng} \mathrm{L}^{-1}$ ) were much higher than those during weekdays (mean $52.3 \mathrm{ng} \mathrm{L}^{-1}$ ). This may be due to the fact that the swimming pools were heavily used and introduced more parabens during the weekends (Moreno-Gonzalez et al. 2014).

\section{Weekly dynamics of parabens, chlorinated parabens, and PHBA}

Generally, swimming pools involve constant recirculation of chlorinated water and continuous loading of various organic pollutants from swimmers over several months, which may change the levels of parabens during this period. A series of samples were analyzed in order to investigate the dynamic change trend of selected compounds from a cold weather period (March) to a hot weather period (June). The concentrations of $\sum$ PBs, $\sum$ Cl-PBs, PHBA, and TOC in a school indoor swimming pool during a 14 -week period were present in Fig. 4.

Significant changes were observed in their levels during this period. It is interesting that the highest levels of contaminants ( $\sum$ PBs $143 \mathrm{ng} \mathrm{L}^{-1}$; $\sum$ Cl-PBs $52.7 \mathrm{ng} \mathrm{L}^{-1}$; PHBA $548 \mathrm{ng} \mathrm{L}^{-1}$ ) were found during the cold weather period with low number of swimmers. In general, when swimming pools utilize a water recirculation system for a long period,
Fig. 3 Box-and-whisker plots of concentrations of parabens and chlorinated parabens in different types of swimming pools

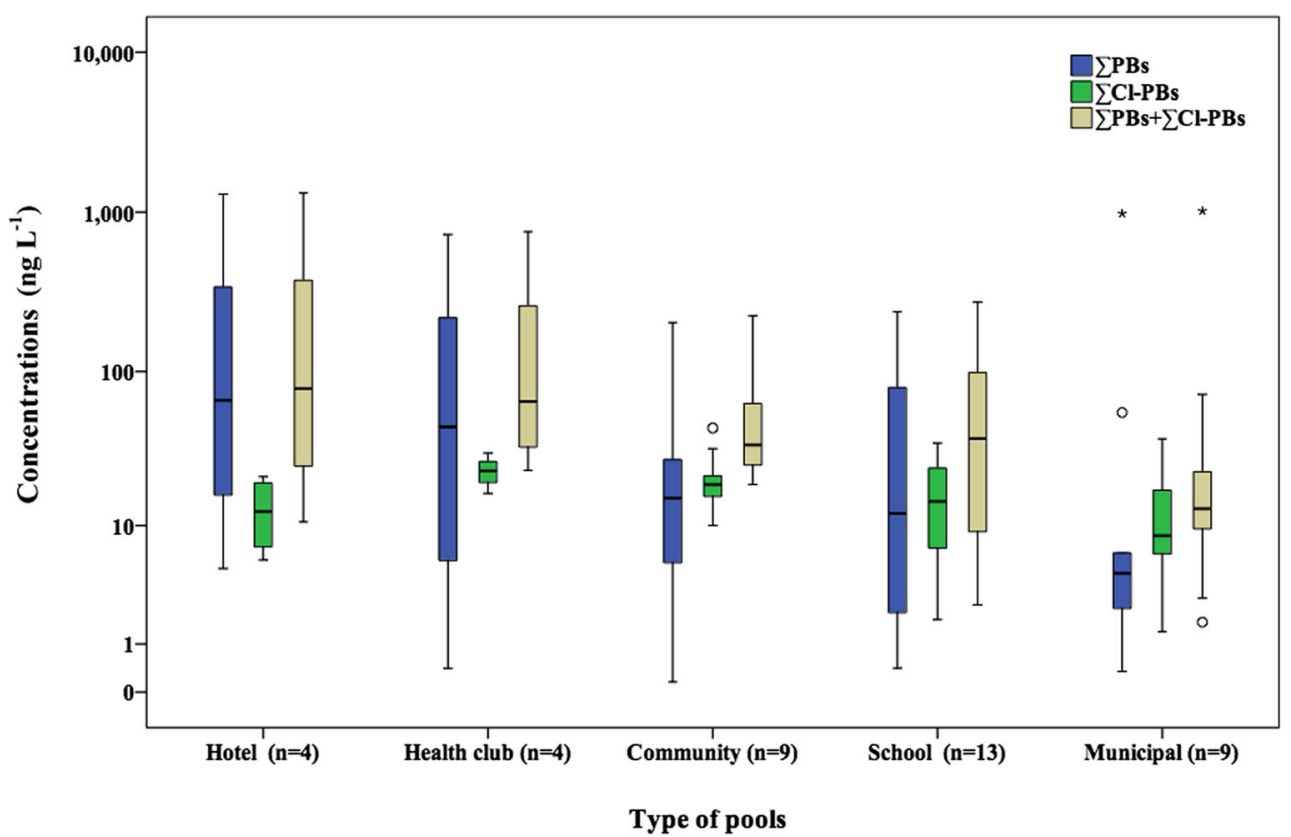


Fig. 4 Dynamics of parabens, chlorinated parabens, PHBA, and TOC in water from a school indoor swimming pool over a 14-week period

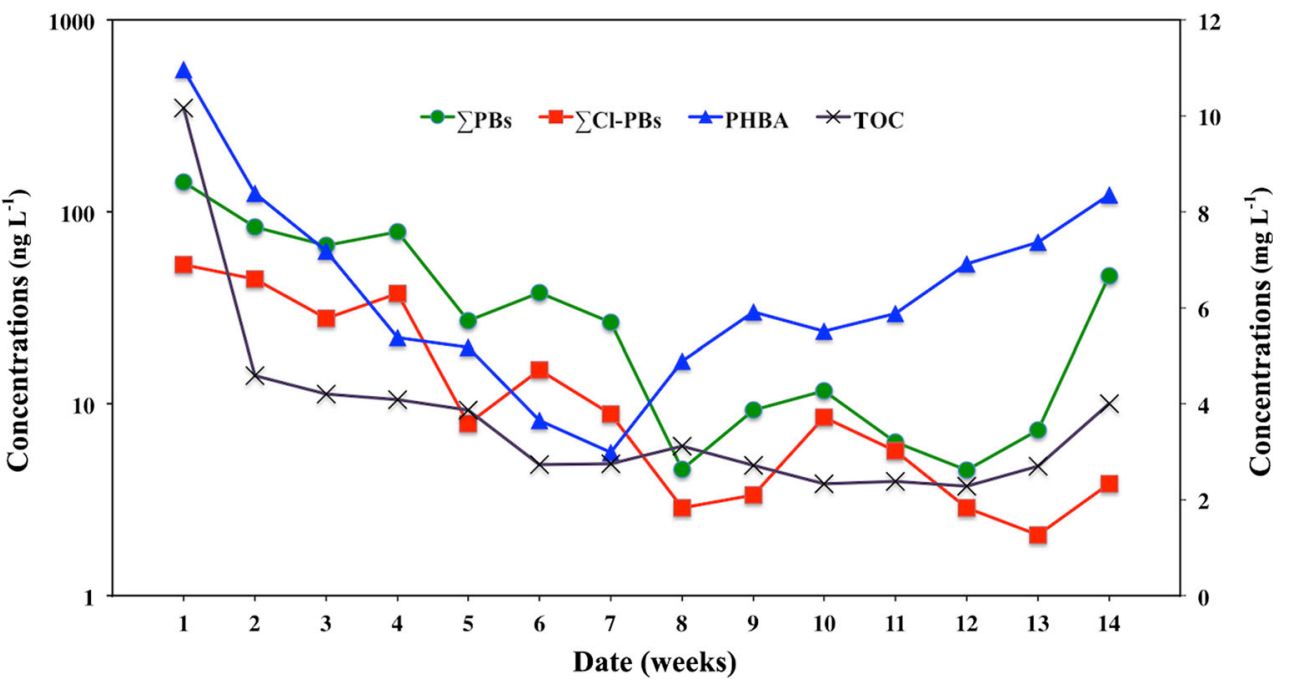

continuous loading of the water with organic carbon from swimmers can accumulate in swimming pool water (Zwiener et al. 2007). The levels of TOC could factually reflect the operating conditions of the swimming pools. Therefore, high values of TOC $\left(10.2 \mathrm{mg} \mathrm{L}^{-1}\right)$ indicated that the pool water was not replaced for a considerable time before the first week of March, resulting in very long water age and high contaminant concentrations. In the second week of March, owing to the thorough water replacement, the concentration of TOC was rapidly reduced by $75 \%$. Meanwhile, the concentrations of $\sum$ PBs, $\Sigma$ Cl-PBs, and PHBA also revealed a great reduction due to the water replacement. In the next 5 weeks, the concentrations of $\sum \mathrm{PBs}, \sum \mathrm{Cl}-\mathrm{PBs}$, and PHBA were sequentially decreased by gradual dilution with infusion of fresh tap water. After the process of diluting was completed in the eighth week, the concentrations of $\sum \mathrm{PBs}$ and $\sum \mathrm{Cl}-\mathrm{PBs}$ exhibited a continuous decrease to the lowest levels, while PHBA started to increase. From the ninth week to the next 4 weeks, the TOC was observed at a relatively steady level (2.27$2.70 \mathrm{mg} \mathrm{L}^{-1}$ ), while the concentrations of $\sum \mathrm{PBs}$ and $\sum$ Cl-PBs exhibited some fluctuations during this period. In the 14th week, the concentrations of $\sum \mathrm{PBs}$ and $\sum \mathrm{Cl}$ PBs increased to 46.5 and $3.84 \mathrm{ng} \mathrm{L}^{-1}$, respectively, presumably due to a large increase in swimmers who brought a large amount of parabens into the swimming pool, leading to the formation of the increased amount of $\sum \mathrm{Cl}-\mathrm{PBs}$. It should be noted that the concentration of PHBA (123 $\mathrm{ng} \mathrm{L}^{-1}$ ) revealed more rapid increase than the level of $\sum$ PBs, implying that a large amount of PHBA was produced by the degradation of parabens in this process.

Swimming pool water is a dynamic environment, and the average pollutant concentration changes with time markedly. The operation of a swimming pool would also affect the levels of parabens with several factors, such as the swimmers' behavior in the swimming pool, service hours, replacement frequency of the swimming pool, as well as contaminants brought into the swimming pool (Zwiener et al. 2007). This result provides a general trend of the levels of parabens in water of swimming pool. The information regarding such factors is rather scarce, and the correlation between the levels of parabens and these factors needs to be further explored.

\section{Human exposure assessment}

When swimming in the pool water, humans can be exposed to parabens through three different exposure routes: inhalation, dermal absorption, and ingestion. Due to their low volatility, inhalation is not expected to be an important exposure route for parabens (Gosens et al. 2014; Haman et al. 2015). Generally, accidental ingestion and dermal absorption are the major routes of exposure to parabens via swimming pool water. The total daily exposure of parabens was calculated by summing the intake from dermal absorption and ingestion, as shown in the following formula:

$D_{\text {total }}=D_{\text {ingestion }}+D_{\text {dermal }}$

The dose due to ingestion of parabens in swimming pool water $\left(D_{\text {ingestion }}\right.$, ng day $\left.{ }^{-1}\right)$ was calculated using the equation:

$D_{\text {ingestion }}=C_{W} \times I R \times S T \times S F \times B I$

where $C_{W}$ is the concentration of parabens in swimming pool water (ng $\mathrm{L}^{-1}$ ), and the mean and maximum concentrations of parabens were used for average and high exposure scenarios, respectively; $I R$ is the ingestion rate $\left(\mathrm{L} \mathrm{h}^{-1}\right) ; S T$ is the swimming time and was assumed to be $2 \mathrm{~h}$ for each swimming; $S F$ is the swimming frequency (times $\mathrm{L}^{-1}$ ), which are assumed to be 0.5 time per day in hot weather; $B I$ is the bioavailability of these compounds in gastrointestinal, which are assumed to be $100 \%$, providing the maximum ingestion dose ( $\mathrm{Xu}$ et al. 2002). 
The dose due to dermal contact with parabens in swimming pool water $\left(D_{\text {dermal }}\right.$, ng day $\left.^{-1}\right)$ was calculated using the equation:

$D_{\text {dermal }}=D A \times S A \times S F$

where $S A$ is the skin surface area available for contact $\left(\mathrm{cm}^{2}\right) ; S F$ is the swimming frequency (times day ${ }^{-1}$ ); $D A$ is the absorbed dose per unit area $\left(\mathrm{ng} \mathrm{cm}^{-2}\right)$, which is calculated for parabens as follows:

$$
\begin{aligned}
& \text { If } S T<{ }^{*}, D A=2 \\
& \text { If } S T>{ }^{*} t, D A= \\
& \quad \begin{aligned}
& 10^{-3} \times K p \\
& \times C W\left[\frac{S T}{1+B}+2 \tau\left(\frac{1+3 B+3 B^{2}}{1+2 B+B^{2}}\right)\right]
\end{aligned}
\end{aligned}
$$

where $C_{w}$ is the concentrations of parabens in swimming pool water (ng L $\left.{ }^{-1}\right) ; K_{p}$ is the dermal permeability coefficient of compound in water $\left(\mathrm{cm} \mathrm{h}^{-1}\right)$; $\tau$ is the lag time (h); $S T$ is the swimming time and was assumed to be $2 \mathrm{~h}$ for each swimming; $\mathrm{t}\left({ }^{*}\right)$ is the time to reach steady state $(\mathrm{h})=2.4 \tau ; B$ is the dimensionless ratio of the permeability coefficient of a compound through the stratum corneum relative to its permeability coefficient across the viable epidermis (dimensionless). According to the US Environmental Protection Agency (EPA) Exposure Factors Handbook (USEPA 2011), these parameters are calculated in the supplementary materials, and detailed information of these values is listed in Table 2.

It is reported that significant differences were observed in the ingestion of pool water between adults and children (Schets et al. 2011). The average volumes of water swallowed per hour by adults and children during an average visit to a swimming pool are 49 and $21 \mathrm{~mL}$, respectively (Dufour et al. 2006). Additionally, there is a marked physical difference between the skin surface areas of the adults and the children, and the recommended SA exposed to water for adults and the children are 18,000 and $6600 \mathrm{~cm}^{2}$, respectively. Therefore, two cases of adults and the children should be discussed separately.

The daily exposures of parabens from swimming are showed in Table 3. The maximum daily exposures of parabens through ingestion and dermal absorption from water were estimated as 52.4 and $335 \mathrm{ng} \mathrm{day}^{-1}$ for adults, respectively. The results clearly indicate that dermal absorption is the most important pathway and that uptake through ingestions is not important for adults. However, as for children, the maximum values through ingestion and dermal absorption were 122 and $123 \mathrm{ng} \mathrm{day}^{-1}$, respectively, showing that dermal absorption and ingestion contributed equally to the total body burden of parabens in swimming pool.

The total daily exposures of parabens from swimming were 388 and 245 ng day $^{-1}$ for adults and children, respectively. In the present study, the maximum estimated daily intake (EDI) for total parabens from swimming pool water, based on body weights of 70 and $15 \mathrm{~kg}$ for adults and children, were 5.39 and $15.9 \mathrm{n} \mathrm{kg} \mathrm{k}^{-1}$ body weight per day, respectively, indicating that children are more sensitive than adults to the potential health risks. Previous studies have reported that the EDI for the total parabens for adults and children are 74.4 and $40.8 \mu \mathrm{g} \mathrm{kg}^{-1}$ body weight per day, respectively (Asimakopoulos et al. 2014; $\mathrm{Ma}$ et al. 2013). These values were several orders of magnitude higher than the maximum EDI for the total parabens from swimming pool water, suggesting that human exposure to

\begin{tabular}{|c|c|c|c|c|c|c|c|c|c|}
\hline \multirow[t]{2}{*}{ Analytes } & \multirow[t]{2}{*}{$\log$ Kow } & \multirow[t]{2}{*}{$\mathrm{MW}\left(\mathrm{g} \mathrm{mol}^{-1}\right)$} & \multirow[t]{2}{*}{$K_{p}\left(\mathrm{~cm} \mathrm{~h}^{-1}\right)$} & \multirow[t]{2}{*}{$B$} & \multirow[t]{2}{*}{$D_{s c}\left(\mathrm{~cm} \mathrm{~h}^{-1}\right)$} & \multirow[t]{2}{*}{$\tau(h)$} & \multirow[t]{2}{*}{ t $(\mathrm{h})$} & \multicolumn{2}{|c|}{$D A\left(\mathrm{ng} \mathrm{cm}^{-2}\right)$} \\
\hline & & & & & & & & Max & Mean \\
\hline $\mathrm{MeP}$ & 1.66 & 152.15 & 0.0028 & 0.0133 & $2.23 \times 10^{-4}$ & 0.747 & 1.79 & $8.66 \times 10^{-3}$ & $8.51 \times 10^{-4}$ \\
\hline EtP & 2.19 & 166.17 & 0.0051 & 0.0253 & $1.84 \times 10^{-4}$ & 0.905 & 2.17 & $2.09 \times 10^{-3}$ & $1.25 \times 10^{-4}$ \\
\hline PrP & 2.71 & 180.2 & 0.0095 & 0.0490 & $1.55 \times 10^{-4}$ & 1.072 & 2.57 & $1.02 \times 10^{-2}$ & $7.06 \times 10^{-4}$ \\
\hline $\mathrm{BuP}$ & 3.24 & 194.23 & 0.0178 & 0.0954 & $1.30 \times 10^{-4}$ & 1.285 & 3.08 & $3.89 \times 10^{-3}$ & $1.60 \times 10^{-4}$ \\
\hline $\mathrm{HeP}$ & 4.41 & 236.31 & 0.0613 & 0.3624 & $7.53 \times 10^{-5}$ & 2.211 & 5.31 & $2.14 \times 10^{-5}$ & 0 \\
\hline $\mathrm{BzP}$ & 3.56 & 228.24 & 0.0187 & 0.1087 & $8.35 \times 10^{-5}$ & 1.992 & 4.78 & $6.73 \times 10^{-4}$ & $1.20 \times 10^{-4}$ \\
\hline $\mathrm{OcP}$ & 4.88 & 250.34 & 0.1044 & 0.6353 & $6.28 \times 10^{-5}$ & 2.649 & 6.36 & $4.58 \times 10^{-4}$ & $1.20 \times 10^{-4}$ \\
\hline 3-Cl-MeP & 2.27 & 186.59 & 0.0045 & 0.0236 & $1.43 \times 10^{-4}$ & 1.164 & 2.79 & $1.42 \times 10^{-4}$ & $2.83 \times 10^{-5}$ \\
\hline 3,5-2Cl-MeP & 2.88 & 221.04 & 0.0073 & 0.0417 & $1.43 \times 10^{-4}$ & 1.816 & 4.36 & $1.39 \times 10^{-3}$ & $1.87 \times 10^{-4}$ \\
\hline 3,5-2Cl-EtP & 3.32 & 235.06 & 0.0119 & 0.0702 & $9.16 \times 10^{-5}$ & 2.175 & 5.22 & $1.66 \times 10^{-3}$ & $7.61 \times 10^{-4}$ \\
\hline PHBA & 1.39 & 138.12 & 0.0022 & 0.0099 & $2.67 \times 10^{-4}$ & 0.623 & 1.50 & $8.08 \times 10^{-3}$ & $1.88 \times 10^{-3}$ \\
\hline
\end{tabular}
parabens from swimming pools is negligible. However,

Table 2 Dermal exposure parameters of target compounds

$K_{p}$ is the dermal permeability coefficient of compound in water $\left(\mathrm{cm} \mathrm{h}^{-1}\right) ; B$ is the dimensionless ratio of the permeability coefficient of a compound through the stratum corneum relative to its permeability coefficient across the viable epidermis (dimensionless); $D_{S C}$ is the effective diffusion coefficient of the chemical in the stratum corneum; $\tau$ is the lag time (h); ${ }_{\mathrm{t}}^{*}$ is the time to reach steady state $(\mathrm{h})=2.4 \tau ; D A$ is the absorbed dose per unit area (ng $\mathrm{cm}^{-2}$ ) 
Table 3 Daily ingestion doses and dermal doses of the parabens from daily swimming activities (ng day ${ }^{-1}$ )

\begin{tabular}{|c|c|c|c|c|c|c|c|}
\hline \multirow[t]{2}{*}{ Analytes } & \multirow[t]{2}{*}{ Groups } & \multicolumn{2}{|l|}{ Ingestion } & \multicolumn{2}{|l|}{ Dermal } & \multicolumn{2}{|l|}{ Total } \\
\hline & & Maximum & Mean & Maximum & Mean & Maximum & Mean \\
\hline \multirow[t]{2}{*}{$\mathrm{MeP}$} & Adult & 18.3 & 1.80 & 77.9 & 7.66 & 90.7 & 9.31 \\
\hline & Child & 42.7 & 4.20 & 28.6 & 2.81 & 67.2 & 6.90 \\
\hline \multirow[t]{2}{*}{ EtP } & Adult & 2.31 & 0.14 & 18.8 & 1.13 & 21.1 & 1.26 \\
\hline & Child & 5.39 & 0.32 & 6.89 & 0.41 & 12.3 & 0.74 \\
\hline \multirow[t]{2}{*}{$\operatorname{PrP}$} & Adult & 5.59 & 0.39 & 91.9 & 6.36 & 97.5 & 6.74 \\
\hline & Child & 13.0 & 0.90 & 33.7 & 2.33 & 46.7 & 3.23 \\
\hline \multirow[t]{2}{*}{$\mathrm{BuP}$} & Adult & 1.03 & 0.04 & 35.0 & 1.44 & 36.0 & 1.48 \\
\hline & Child & 2.41 & 0.10 & 12.8 & 0.53 & 15.2 & 0.63 \\
\hline \multirow[t]{2}{*}{$\mathrm{BzP}$} & Adult & 0.14 & 0.02 & 6.06 & 1.08 & 6.19 & 1.10 \\
\hline & Child & 0.32 & 0.06 & 2.22 & 0.40 & 2.54 & 0.45 \\
\hline \multirow[t]{2}{*}{$\mathrm{HeP}$} & Adult & 0.00 & 0.00 & 0.19 & 0.00 & 0.19 & 0.00 \\
\hline & Child & 0.00 & 0.00 & 0.07 & 0.00 & 0.07 & 0.00 \\
\hline \multirow[t]{2}{*}{$\mathrm{OcP}$} & Adult & 0.01 & 0.00 & 4.12 & 1.08 & 4.14 & 1.08 \\
\hline & Child & 0.03 & 0.01 & 1.51 & 0.39 & 1.55 & 0.41 \\
\hline \multirow[t]{2}{*}{ 3-Cl-MeP } & Adult & 0.16 & 0.03 & 1.28 & 0.25 & 6.95 & 0.63 \\
\hline & Child & 0.37 & 0.07 & 0.47 & 0.09 & 4.04 & 0.37 \\
\hline \multirow[t]{2}{*}{ 3,5-2Cl-MeP } & Adult & 0.76 & 0.10 & 12.5 & 1.68 & 2.98 & 1.14 \\
\hline & Child & 1.77 & 0.24 & 4.59 & 0.62 & 1.43 & 0.54 \\
\hline \multirow[t]{2}{*}{ 3,5-2Cl-EtP } & Adult & 0.51 & 0.23 & 14.9 & 6.85 & 15.4 & 7.08 \\
\hline & Child & 1.19 & 0.54 & 5.47 & 2.51 & 6.7 & 3.05 \\
\hline \multirow[t]{2}{*}{ PHBA } & Adult & 23.6 & 5.48 & 72.8 & 16.9 & 96 & 22.7 \\
\hline & Child & 55.0 & 12.8 & 26.7 & 6.21 & 81.7 & 19.2 \\
\hline \multirow[t]{2}{*}{ Total } & Adult & 52.4 & 8.2 & 335 & 44.4 & 388 & 52.7 \\
\hline & Child & 122 & 19.2 & 123 & 16.3 & 245 & 35.5 \\
\hline
\end{tabular}

because the young children are sensitive subpopulation for health effects from chemical exposures in swimming pool water, it is important to assess the potential risks of parabens to these susceptible populations in the future work.

\section{Conclusions}

In the present study, 12 target compounds, including seven parabens, four chlorinated parabens, and their main hydrolysis product (PHBA), were found in water samples from 39 swimming pools in Beijing. The samples from different swimming pools showed very similar composition profiles of parabens, indicating their universal usages and extensive pollution in swimming pools. Significant differences were observed for total concentrations of parabens in water samples among 39 pools, and the operation of swimming pools could affect the levels of parabens to some extent. Compared to previous studies, the levels of parabens in this study were relatively high. The potential risks of parabens in swimming pools need to be further investigated, and the threat of these parabens in swimming pool water should be concerned.
Acknowledgments This work was supported by the National Basic Research Program of China (2014CB114402), the National Natural Science Foundation of China (No. 21407008, 21477143, 21321004, and 21277011), the Strategic Priority Research Program of the Chinese Academy of Sciences (XDB14010201), the Fundamental Research Funds for the Central Universities (FRF-BR-13-005), China Postdoctoral Science Foundation (2014 M550619), and State Key Laboratory of Environmental Chemistry and Ecotoxicology, Research Center for EcoEnvironmental Sciences, Chinese Academy of Sciences (KF2013-07).

\section{References}

Abd El-Salam MM (2012) Assessment of water quality of some swimming pools: a case study in Alexandria, Egypt. Environ Monit Assess 184:7395-7406

Andersen FA (2008) Final amended report on the safety assessment of methylparaben, ethylparaben, propylparaben, isopropylparaben, butylparaben, isobutylparaben, and benzylparaben as used in cosmetic products. Int $\mathrm{J}$ Toxicol 27:1-82

Asimakopoulos AG, Thomaidis NS, Kannan K (2014) Widespread occurrence of bisphenol A diglycidyl ethers, p-hydroxybenzoic acid esters (parabens), benzophenone type-UV filters, triclosan, and triclocarban in human urine from Athens, Greece. Sci Total Environ 470-471:1243-1249 
Bedoux G, Roig B, Thomas O, Dupont V, Le Bot B (2012) Occurrence and toxicity of antimicrobial triclosan and by-products in the environment. Environ Sci Pollut Res 19:1044-1065

Bernard A, Carbonnelle S, de Burbure C, Michel O, Nickmilder M (2006) Chlorinated pool attendance, atopy, and the risk of asthma during childhood. Environ Health Perspect 114:1567-1573

Bledzka D, Gromadzinska J, Wasowicz W (2014) Parabens. From environmental studies to human health. Environ Int 67:27-42

Boberg J, Taxvig C, Christiansen S, Hass U (2010) Possible endocrine disrupting effects of parabens and their metabolites. Reprod Toxicol 30:301-312

Brausch JM, Rand GM (2011) A review of personal care products in the aquatic environment: environmental concentrations and toxicity. Chemosphere 82:1518-1532

Canosa P, Rodriguez I, Rubi E, Negreira N, Cela R (2006) Formation of halogenated by-products of parabens in chlorinated water. Anal Chim Acta 575:106-113

Carmona E, Andreu V, Pico Y (2014) Occurrence of acidic pharmaceuticals and personal care products in Turia River Basin: from waste to drinking water. Sci Total Environ 484:53-63

Chowdhury S, Alhooshani K, Karanfil T (2014) Disinfection byproducts in swimming pool: occurrences, implications and future needs. Water Res 53:68-109

Dobbins LL, Usenko S, Brain RA, Brooks BW (2009) Probabilistic ecological hazard assessment of parabens using Daphnia Magna and Pimephales Promelas. Environ Toxicol Chem 28:2744-2753

Dufour AP, Evans O, Behymer TD, Cantú R (2006) Water ingestion during swimming activities in a pool: a pilot study. J Water Health 4:425-430

Golden R, Gandy J, Vollmer G (2005) A review of the endocrine activity of parabens and implications for potential risks to human health. Crit Rev Toxicol 35:435-458

Gonzalez-Doncel M, Garcia-Maurino JE, San Segundo L, Beltran EM, Sastre S, Fernandez Torija C (2014) Embryonic exposure of medaka (Oryzias latipes) to propylparaben: effects on early development and post-hatching growth. Environ Pollut 184:360-369

Gonzalez-Marino I, Quintana JB, Rodriguez I, Cela R (2009) Simultaneous determination of parabens, triclosan and triclocarban in water by liquid chromatography/electrospray ionisation tandem mass spectrometry. Rapid Commun Mass Spectrom 23:1756-1766

Gosens I, Delmaar CJ, Ter Burg W, de Heer C, Schuur AG (2014) Aggregate exposure approaches for parabens in personal care products: a case assessment for children between 0 and 3 years old. J Expo Sci Environ Epidemiol 24:208-214

Guo Y, Wang L, Kannan K (2014) Phthalates and parabens in personal care products from china: concentrations and human exposure. Arch Environ Contam Toxicol 66:113-119

Haman C, Dauchy X, Rosin C, Munoz J-F (2015) Occurrence, fate and behavior of parabens in aquatic environments: a review. Water Res $68: 1-11$

Harvey PW, Everett DJ (2006) Regulation of endocrine-disrupting chemicals: critical overview and deficiencies in toxicology and risk assessment for human health. Best Pract Res Clin Endocrinol Metab 20:145-165

Ishiwatari S, Suzuki T, Hitomi T, Yoshino T, Matsukuma S, Tsuji T (2007) Effects of methyl paraben on skin keratinocytes. J Appl Toxicol 27:1-9

Jonkers N, Kohler HPE, Dammshauser A, Giger W (2009) Mass flows of endocrine disruptors in the Glatt River during varying weather conditions. Environ Pollut 157:714-723

Jonkers N, Sousa A, Galante-Oliveira S, Barroso CM, Kohler H-PE, Giger W (2010) Occurrence and sources of selected phenolic endocrine disruptors in Ria de Aveiro, Portugal. Environ Sci Pollut Res $17: 834-843$
Karpuzoglu E, Holladay SD, Gogal RM Jr (2013) Parabens: potential impact of low-affinity estrogen receptor binding chemicals on human health. J Toxicol Environ Heal B 16:321-335

Kim H, Shim J, Lee S (2002) Formation of disinfection by-products in chlorinated swimming pool water. Chemosphere 46:123-130

Lee HB, Peart TE, Svoboda ML (2005) Determination of endocrinedisrupting phenols, acidic pharmaceuticals, and personal-care products in sewage by solid-phase extraction and gas chromatographymass spectrometry. J Chromatogr A 1094:122-129

Lopez-Darias J, Pino V, Meng Y, Anderson JL, Afonso AM (2010) Utilization of a benzyl functionalized polymeric ionic liquid for the sensitive determination of polycyclic aromatic hydrocarbons, parabens and alkylphenols in waters using solid-phase microextraction coupled to gas chromatography-flame ionization detection. J Chromatogr A 1217:7189-7197

Ma W-L, Wang L, Guo Y, Liu L-Y, Qi H, Zhu N-Z, Gao C-J, Li Y-F, Kannan K (2013) Urinary concentrations of parabens in chinese young adults: implications for human exposure. Arch Environ Contam Toxicol 65:611-618

Meeker JD, Yang T, Ye XY, Calafat AM, Hauser R (2011) Urinary concentrations of parabens and serum hormone levels, semen quality parameters, and sperm DNA damage. Environ Health Perspect 119: $252-257$

Moreno-Gonzalez R, Rodriguez-Mozaz S, Gros M, Perez-Canovas E, Barcelo D, Leon VM (2014) Input of pharmaceuticals through coastal surface watercourses into a Mediterranean lagoon (Mar Menor, SE Spain): sources and seasonal variations. Sci Total Environ 490:59-72

Ngo MA, Maibach HI (2010) Dermatotoxicology: historical perspective and advances. Toxicol Appl Pharmacol 243:225-238

Nunez L, Tadeo JL, Garcia-Valcarcel AI, Turiel E (2008) Determination of parabens in environmental solid samples by ultrasonic-assisted extraction and liquid chromatography with triple quadrupole mass spectrometry. J Chromatogr A 1214:178-182

Pasquarella C, Veronesi L, Napoli C, Castaldi S, Pasquarella ML, Saccani E, Colucci ME, Auxilia F, Galle F, Di Onofrio V, Tafuri S, Signorelli C, Liguori G (2013) Swimming pools and health-related behaviours: results of an Italian multicentre study on showering habits among pool users. Public Health 127:614-619

Pasquarella C, Veronesi L, Napoli C, Castaldi S, Pasquarella ML, Saccani E, Colucci ME, Auxilia F, Galle F, Di Onofrio V, Tafuri S, Signorelli C, Liguori G (2014) What about behaviours in swimming pools? Results of an Italian multicentre study. Microchem J 112:190-195

Piao C, Chen L, Wang Y (2014) A review of the extraction and chromatographic determination methods for the analysis of parabens. $\mathrm{J}$ Chromatogr B 969:139-148

Regueiro J, Becerril E, Garcia-Jares C, Llompart M (2009a) Trace analysis of parabens, triclosan and related chlorophenols in water by headspace solid-phase microextraction with in situ derivatization and gas chromatography-tandem mass spectrometry. J Chromatogr A 1216:4693-4702

Regueiro J, Llompart M, Psillakis E, Garcia-Monteagudo JC, GarciaJares C (2009b) Ultrasound-assisted emulsification-microextraction of phenolic preservatives in water. Talanta 79:1387-1397

Savage JH, Matsui EC, Wood RA, Keet CA (2012) Urinary levels of triclosan and parabens are associated with aeroallergen and food sensitization. J Allergy Clin Immunol 130:453-460

Schets FM, Schijven JF, Husman AMD (2011) Exposure assessment for swimmers in bathing waters and swimming pools. Water Res 45: 2392-2400

Tavares RS, Martins FC, Oliveira PJ, Ramalho-Santos J, Peixoto FP (2009) Parabens in male infertility-Is there a mitochondrial connection? Reprod Toxicol 27:1-7

Teo TL, Coleman HM, Khan SJ (2015) Chemical contaminants in swimming pools: occurrence, implications and control. Environ Int 76: $16-31$ 
Terasaki M, Makino M (2008) Determination of chlorinated by-products of parabens in swimming pool water. Int J Environ Anal Chem 88: 911-922

Terasaki M, Makino M, Tatarazako N (2009) Acute toxicity of parabens and their chlorinated by-products with Daphnia magna and Vibrio fischeri bioassays. J Appl Toxicol 29:242-247

Terasaki M, Takemura Y, Makino M (2012) Paraben-chlorinated derivatives in river waters. Environ Chem Lett 10:401-406

USEPA (2011) Exposure factors handbook: 2011 edition. National Center for Environmental Assessment, Washington, DC

Wang L, Liao CY, Liu F, Wu Q, Guo Y, Moon HB, Nakata H, Kannan K (2012) Occurrence and human exposure of p-hydroxybenzoic acid esters (parabens), bisphenol a diglycidyl ether (BADGE), and their hydrolysis products in indoor dust from the United States and three East Asian Countries. Environ Sci Technol 46:11584-11593

Westerhoff P, Yoon Y, Snyder S, Wert E (2005) Fate of endocrinedisruptor, pharmaceutical, and personal care product chemicals during simulated drinking water treatment processes. Environ Sci Technol 39:6649-6663
Xiao F, Zhang X, Zhai H, Lo IMC, Tipoe GL, Yang M, Pan Y, Chen G (2012) New halogenated disinfection byproducts in swimming pool water and their permeability across skin. Environ Sci Technol 46: 7112-7119

Xu X, Mariano TM, Laskin JD, Weisel CP (2002) Percutaneous absorption of trihalomethanes, haloacetic acids, and haloketones. Toxicol Appl Pharmacol 184:19-26

Yamamoto H, Tamura I, Hirata Y, Kato J, Kagota K, Katsuki S, Yamamoto A, Kagami Y, Tatarazako N (2011) Aquatic toxicity and ecological risk assessment of seven parabens: individual and additive approach. Sci Total Environ 410:102-111

Yeh RY, Farre MJ, Stalter D, Tang JY, Molendijk J, Escher BI (2014) Bioanalytical and chemical evaluation of disinfection by-products in swimming pool water. Water Res 59:172-184

Zwiener C, Richardson SD, De Marini DM, Grummt T, Glauner T, Frimmel FH (2007) Drowning in disinfection byproducts? Assessing swimming pool water. Environ Sci Technol 41:363-372 